\title{
Prevalence of needle-stick and sharp object injuries and its associated factors among staff nurses in Dessie referral hospital Amhara region, Ethiopia, 2018
}

\author{
Ayele Mamo Abebe ${ }^{1 *}$, Mesfin Wudu Kassaw ${ }^{2}$ and Nathan Estifanos Shewangashaw ${ }^{2,3}$
}

\begin{abstract}
Objective: The aim of this study was to assess the prevalence of needle-stick and sharp object injuries among staff nurses in Dessie referral hospital, Amhara region, Ethiopia, 2018.

Results: Among the 151 study participants, 98 (65\%) respondents were males. Seventy-five (48.1\%) participants had 4-10 years of experience. The overall prevalence of needle stick and sharp object injury among staff nurses in Dessie referral hospital was $43 \%$. In this study, nurses who worked in the emergency department were $11 \times$ more likely to experience needle stick and sharp object injury compared with nurses who worked in outpatient department $\mathrm{P}=0.004[\mathrm{AOR}=11.51195 \% \mathrm{Cl} 2.134,62.09)]$. Participants who were worked in adult health department were $10 x$ more likely experience needle stick and sharp object injury when compared with participants who were worked in outpatient department $\mathrm{P}=0.006[\mathrm{AOR}=9.74295 \% \mathrm{Cl}$ 1.904, 49.859)]. The major implication of these study findings on the health system is the importance of given emphasis for nurses in relation with needle stick and sharp injury.
\end{abstract}

Keywords: Needle stick and sharp object injury, Nurses, Dessie referral hospital

\section{Introduction}

A needle stick injury is a penetration of skin by a needle point, but probably also by other piercing instruments [1]. These problems are a common event in the healthcare environment. These injuries also commonly occur during drawing blood, medication administering, needle recapping and during surgery [2].

In a report by Center for Disease Control and Prevention there is an estimated 600,000 to one million needle stick injuries occurring each year in the world, and about half of which went unreported [3]. Findings of researches on needle stick injury showed that it ranged from 21 to 95\% [4-6]. Needle stick injury has accounted for $86 \%$ of all occupationally related infection transmissions [7].

*Correspondence: ayelemamo12@gmail.com

${ }^{1}$ Department of Nursing, Debre Birhan Health Sciences College, P.O. Box 37, Amhara, Debre Birhan, Ethiopia

Full list of author information is available at the end of the article
Globally, two million health care workers suffer from accidental needle stick injury each year [8]. In UK, a study showed that $37 \%$ needle stick injuries reported at some stage during their career [9]. In Nepal a survey reported that needle stick injury among health care workers was $70.3 \%$ [10].

In developing countries, where the prevalence of HIV infection is the highest in the world, the number of needle stick injuries is also the highest. Additionally, African health care workers suffer an average of two to four needle stick injuries per year and physicians are much less likely to report a needle stick injury than other healthcare professionals [11]. Study revealed that, transitional and developing countries where unnecessary injection is common, the average number of health care injection per person is averagely estimated to be 3.7/year. Generally in developing countries exposure and health impact of NSI are rarely monitored and poorly managed [12]. 
In Turkey study, $44.3 \%$ of the nurse experience a sharp or needle sticks injury during their professional life. These injuries happened persistently when the nurses were removing a needle from rubber or other tough material; recapping a used needle and take apart a device or equipment [13].

In other studies, two-third healthcare workers in hospitals were injured by sharp or needle sticks $[14,15]$. Furthermore, studies report from Addis Ababa, Arba Minch, Bahir Dar and Awi Zone indicated occupational exposure to needle stick and sharp injuries among HCWs were $66.6 \%, 42.1 \%, 18.7 \%$ and $31.0 \%$, respectively [16-19].

In a national survey of Ethiopia, $38 \%$ of health facilities were removed the sharps objects and needles in an open ground [20]. Similarly in other study, 35\% of the health facilities were disposed the dirty syringes and needles in a way that exposed the health workers and the community for injury [21].

For many years, Ethiopia government gave health education on standard precautions and many preventions methods to avoid sharp and needle sticks injuries but, the problem is not decreased.

Therefore, the study aimed to assess the prevalence and associated factors to needle stick and sharp injury among nurses at Dessie referral hospital, Amhara, Ethiopia.

\section{Main text \\ Methods \\ The study area and period}

This study was conducted in Dessie referral hospital, Amhara region; Northeast Ethiopia from February 1-15, 2018. Dessie is the capital city of south Wollo zone and is located in the North eastern part of Ethiopia, at approximately $401 \mathrm{~km}$ from the capital city, Addis Ababa. There were 256 nurses who are working in Dessie referral hospital. The source population and study population was all staff nurses in Dessie referral hospital, Amhara region, Ethiopia.

\section{Study design}

The study design was an institutional based cross sectional study.

\section{Sample size}

To determine the sample size for the study, the following assumptions were considered:

- $\mathrm{P}=31 \%[16]$

- $5 \%$ margin of error $(\mathrm{d}=0.05)$

- $10 \%$ for non-response rate.

The sample size was calculated by using the formula:

$$
\mathrm{n}_{\mathrm{i}}=\frac{\mathrm{z}^{2} \mathrm{p}(1-\mathrm{p})}{\mathrm{d}^{2}}
$$

where $\mathrm{n}=$ sample size

$$
\begin{aligned}
\mathrm{n}_{\mathrm{i}}= & (1.96) \times(1.96) \times 0.31(0.69) /(0.05)(0.05) \text { for population } \\
= & 328(\mathrm{I} \text { use this sample size as it is when the } \\
& \text { study population was greater than } 10,000)
\end{aligned}
$$

But our study population 256 is less than 10,000 the calculation. So, we were used the correction formula to get final sample size, i.e. $n f=\mathrm{n}_{\mathrm{i}} /\left(1+\frac{\mathrm{n}_{\mathrm{i}}}{N}\right)=$ $328 /\left(1+\frac{328}{256}\right)=144$, and we added non-respondent rate of $10 \%$.

Therefore final sample size was 158 .

\section{Sampling procedure}

All 256 nurses working in Dessie referral hospital were considered for the study. Participants were selected by using simple random sampling technique from each department based on proportion until the required sample size obtained (Fig. 1).

\section{Data collection procedure}

Self-administered structured questionnaires were used to collect the data. The questionnaires were taken from different related studies $[16,18,19]$ and necessary modifications were done. A translated Amharic version questionnaire was used to collect data. Four health extension workers for data collectors and two B.Sc. nurses for supervisor were employed.

\section{Data quality control}

Training was given for data collectors and supervisors for 1 day and the questionnaire pretested on 5\% sample size at Boru Meda hospital. The questionnaires was checked by the principal investigators on daily basis for completeness.

\section{Data processing and analysis}

Data were checked for completeness and consistency by principal investigators before data entry. Completed data were entered and coded by number into a commuter software Epi data statistical package and exported to SPSS version 20. Bivariate analysis with a $\mathrm{P}$-value $<0.05$ was employed to select candidate variables for the multivariable logistic regression. All statistical tests were considered significant if $\mathrm{P}$-value $<0.05$. Finding was presented by using frequency, tables and graphs.

\section{Results}

\section{Socio demographic characteristics of study participants}

In this study, 151 participants were participated in the study with the response rate of $95.6 \%$. Among the 151 study participants, 98 (65\%) participants were males. 


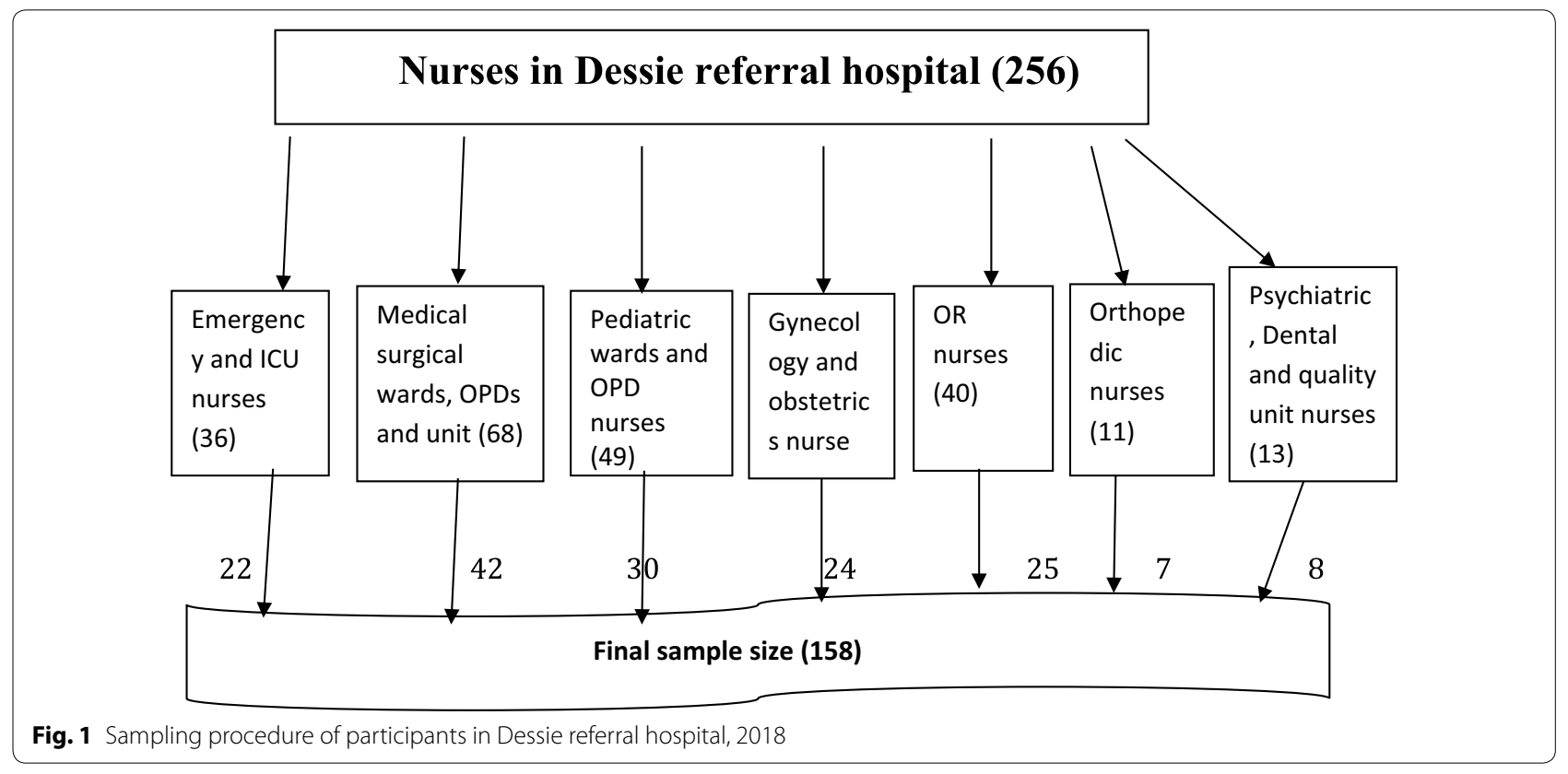

\begin{tabular}{|c|c|c|}
\hline Variables & Frequency $(n=151)$ & Percent (\%) \\
\hline \multicolumn{3}{|l|}{ Gender } \\
\hline Male & 98 & 65.0 \\
\hline Female & 53 & 35.0 \\
\hline \multicolumn{3}{|l|}{ Age } \\
\hline $18-24$ & 40 & 25 \\
\hline $25-30$ & 51 & 36 \\
\hline $31-35$ & 36 & 23.1 \\
\hline $36-40$ & 14 & 9 \\
\hline$>41$ & 10 & 6.5 \\
\hline \multicolumn{3}{|c|}{ Marital status } \\
\hline Single & 72 & 46.7 \\
\hline Married & 79 & 52.3 \\
\hline \multicolumn{3}{|c|}{ Educational status } \\
\hline Diploma & 46 & 30.4 \\
\hline B.sc. & 104 & 69.0 \\
\hline M.sc. & 1 & 0.6 \\
\hline \multicolumn{3}{|c|}{ Work experience (years) } \\
\hline$<3$ & 60 & 39.0 \\
\hline $4-10$ & 75 & 48.1 \\
\hline $11-15$ & 16 & 9.0 \\
\hline$>15$ & 7 & 3.9 \\
\hline
\end{tabular}

B.sc., Bachelor of Science; M.sc., Master of Science

Majority of the respondents (104 (69.0\%)) were BSc holders. Seventy-five (48.1\%) participants had 4-10 years of experience (Table 1$)$.

\section{Work and behavioral factors related characteristics of participants}

Out of the total participants, 49 (32\%) participants were from emergency department. Majority of the study participants $(104(69.0 \%))$ had dissatisfied with their job (Table 2).

\section{Information related to needle stick and sharp object injury} Among the total participants, 89 (59\%) of them reported that there was no post exposure management facility and $72(42.6 \%)$ respondents didn't know which unit they should report when they face needle stick and sharp object injury (Additional file 1: Table S1).

\section{Frequency distribution of type of injection use, type of injury} and occasion of injury occurrences

In relation with the type of needle stick and sharp object injury, $15 \%$ of respondents were reported they faced deep needle stick and sharp object injury while $56 \%$ of respondents faced slight skin penetration (Additional file 2: Figure S1).

\section{Frequency distribution medical devices during needle stick injury}

In this study, syringe with needle (e.g. medication needles) was the device that caused more injury (31\%), followed by suturing needle (30.2\%) (Additional file 3: Figure S2). 
Table 2 Work related and behavioral characteristics of participants

\begin{tabular}{lll}
\hline Variables & $\begin{array}{l}\text { Frequency } \\
(\mathbf{n}=\mathbf{1 5 1 )}\end{array}$ & Percent (\%) \\
\hline Working department & & \\
Emergency & 49 & 32 \\
Pediatric word & 10 & 6.5 \\
Adult ward & 28 & 18.5 \\
OPD, ICU, orthopedic and others & 65 & 43 \\
Job satisfaction & & \\
No & 47 & 31 \\
Yes & 104 & 69 \\
Number of injection per day & & \\
5-10 & 7 & 4.5 \\
10-15 & 12 & 8 \\
15-20 & 37 & 24.5 \\
$>20$ & 95 & 63 \\
Presence of Infection prevention committee & & \\
No & 32 & 21.0 \\
Yes & 119 & 79.0 \\
Vaccination of HBV & & \\
No & 70 & 46.3 \\
Yes & 81 & 53.7 \\
\hline
\end{tabular}

OPD outpatient department; ICU intensive care unit

\section{Frequency distribution of needle, syringes and sharps disposal methods}

Based on this study, protected incineration (76\%) was the commonest disposable method with followed by open dumping (12\%) and open incineration (8\%) (Additional file 4: Figure S3).

\section{The prevalence needle stick and sharp injury}

The overall prevalence of needle stick and sharp object injury among staff nurses in Dessie referral hospital was 43\% (Additional file 5: Figure S4).

\section{Factors associated with needle stick and sharp object injury} In this study, nurses who worked in emergency department were $11 \times$ more likely to experience needle stick and sharp object injury compared with nurses who worked in outpatient department $\mathrm{P}=0.004$ [AOR $=11.511$ 95\% CI 2.134, 62.09)]. Participants who were worked inpatient department were $10 \times$ more likely experience needle stick and sharp object injury when compared with participants who were worked in outpatient department $\mathrm{P}=0.006$ $[A O R=9.742$ 95\% CI 1.904, 49.859)]. Participants who had training on needle stick and sharp object injury were $4 \times$ less likely to experienced needle stick and sharp object injury as compared with those who had not training $\mathrm{P}=0.021[\mathrm{AOR}=3.818,95 \% \mathrm{CI} 1.221-11.935)]$. In this study, nurses who practice recap of needle were $4 \times$ more likely to experience needle stick and sharp object injury when compared with nurses who didn't practice needle recap $[\mathrm{AOR}=4.344,95 \%$ CI $(1.186,15.906)]$. Participants who were not apply universal precaution were $6 \times$ more likely to experienced needle stick and sharp object injury as compared with those who were apply universal precaution $\mathrm{P}=0.001[\mathrm{AOR}=6.413,95 \% \mathrm{CI}$ 2.072-19.850)]. (Additional file 6: Table S2).

\section{Discussion}

According to this study, the prevalence of needle stick and sharp object injury in Dessie referral hospital was $43 \%$. This finding was align with many international studies $[6,10,13]$. On the other hand, the current study finding was higher than the finding of studies done in Malawi (30.3\%), Nigeria (23.1\%), and India (30.1\%) [12, 19, 21] and lower than the studies done in Egypt (62.3\%), Nigeria (68.3\%), Sarajevo, Bosnia and Herzegovina (61.1\%), and Saudi Arabia (50.9\%), [4, 5, 7, 11]. The prevalence of needle stick and sharp object injury reported from the studies conducted in Addis Ababa, Arba Minch, Bahir Dar, Awi were 66\%, 42\%, 33\% and $18.7 \%$, respectively [14-17]. The variation of these findings may be due to the difference of study design used, the socio demographic, and cultural characteristics of study participants. Also it could be due to the difference in the study health facility setups; even the year of the study.

Compared to other groups of health workers, it can be assumed that nurses are more likely to experience needle stick and sharp object injury, because of their working condition. Comparing this study results with a facility based cross sectional study conducted in Awi zone, we found our rates to be higher across the board; nurses vs physician (43\% vs $16 \%)$, nurses vs health officer $(43 \%$ vs $16.7 \%)$, nurses vs laboratory (43\% vs $11.1 \%$,), and nurses vs midwives (43\% vs $25 \%$ ) [17]. The higher magnitude in among nurses might reflect the particular occupational health hazard experienced by this group of health workers.

In this study, nurses who worked in emergency department were $11 \times$ more likely to experience needle stick and sharp object injury compared with nurses who worked in Outpatient department $\mathrm{P}=0.004$ [AOR $=11.511$ 95\% CI $2.134,62.09)]$. The finding was consistent with studies done in Ethiopia, and Nigeria [12, 14].

According to this study, nurses who were worked inpatient department were $10 \times$ more likely experience needle stick and sharp object injury when compared with participants who were worked in outpatient department $\mathrm{P}=0.006[\mathrm{AOR}=9.742$ 95\% CI 1.904, 49.859)]. The finding was in line with studies done in Nigeria and in Awi zone in Ethiopia, [14, 17]. 
Unlike the study conducted in Arba Minch general hospital, Ethiopia [15], study subjects who had training on needle stick and sharp object injury were $4 \times$ less likely to experienced needle stick and sharp object injury as compared with those who had not training in this study. The difference may be more education and training might be given about needle stick injury and infection prevention in this study. Education and training is the right tools to bring behavioral change about infection prevention and safety measures.

In this study, nurses who practice recap of needle were $4 \times$ more likely to experience needle stick and sharp object injury when compared with nurses who didn't practice needle recap $[\mathrm{AOR}=4.344,95 \%$ CI $(1.186$, 15.906)]. It was in line with the studies conducted in Ethiopia, America and Philippines which showed that recap of needle is a risk factor for needle stick and sharp injury $[2,3,10,20]$.

Based on this study, nurses who were not apply universal precaution were $6 \times$ more likely to experienced needle stick and sharp object injury as compared with those who were apply universal precaution $\mathrm{P}=0.001[\mathrm{AOR}=6.413$, 95\% CI 2.072-19.850)]. This study is in line with the study done in Awi Zone [17].

\section{Conclusions}

In this study, prevalence of needle stick and sharp object injury among staff nurses in Dessie referral hospital was 43\%. Apply universal precaution, working department, training on needle stick and sharp object injury and recap of needle had shown a significant association with needle stick and sharp object injury. Education and training should be given for nurses on this issue to reduce this problem.

\section{Limitations}

Cross sectional study design had no shown cause-effect relationship (Chicken-eggs dilemma). It would be better if qualitative approach study was triangulated to investigate further factors on needle stick and sharp object injury.

\section{Additional files}

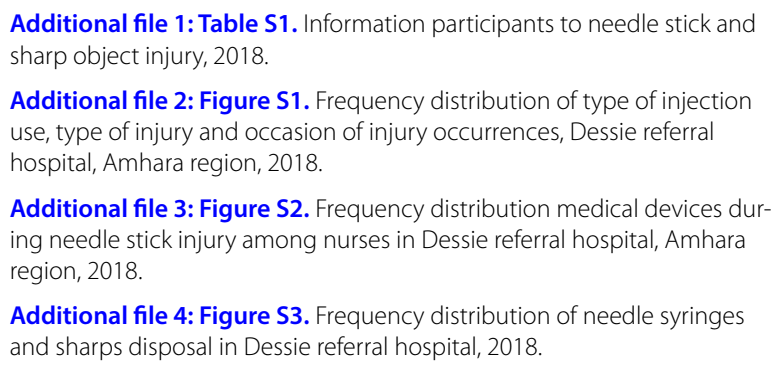

Additional file 5: Figure S4. Prevalence of needle stick and sharp injury among nurses in Dessie referral hospital, 2018.

Additional file 6: Table S2. Bivariate and multivariate logistic regression analysis of factors associated with needle stick and sharp object injury in Dessie referral hospital, Ethiopia 2018.

\section{Abbreviations}

HBV: hepatitis B virus; HCV: hepatitis C virus; HCW: health care workers; HIV: human immunodeficiency virus; NSI: needle stick injury; PEP: post exposure prophylaxis; ICU: intensive care unit.

\section{Authors' contributions}

All authors wrote the research, developed the questionnaire, analyzed the data and wrote the paper and interpreting of the findings as well as participating on the preparation of the manuscript. MW and NE supervised the data collection, contributed to the interpretation of the findings. AM and MW trained data collectors, participated on the preparation of the manuscript. All authors read and approved the final manuscript.

\section{Author details}

${ }^{1}$ Department of Nursing, Debre Birhan Health Sciences College, P.O. Box 37, Amhara, Debre Birhan, Ethiopia. ${ }^{2}$ Department of Nursing, College of Health Sciences, Woldia University, P.O. Box 400, Amhara, Weldiya, Ethiopia. ${ }^{3}$ Public Health Department, Woldia University, P.O. Box 400, Amhara, Weldiya, Ethiopia.

\section{Acknowledgements}

The authors would like to acknowledge Woldia university financial support and Woldia University for providing sponsoring ship. Dessie town health Administrative office and all study participants are acknowledged for their cooperation during sample collection.

\section{Competing interests}

The authors declare that they have no competing interests.

\section{Availability of data and materials}

All data are available through this manuscript.

\section{Consent for publication}

Not applicable.

\section{Ethics approval and consent to participate}

Ethical clearance was obtained from Woldia University, ethical review board and permission was given from Dessie town health administrative office and Dessie referral hospital. The research proposal was evaluated and approved by the Research Ethics Review Committee [HRERC 0710/2018] of college of health sciences, Woldia University and ethical clearance was obtained. Official cooperation and permission was obtained from Dessie town health administrative office and Dessie referral hospital. Moreover, prior to commencing the study, a written informed consent was obtained from each respondent before data collection. Written consent was found from a respondent. Participants were allowed to refuse or discontinue participation at any time they want. Information was recorded namelessly and confidentiality were assured throughout the study period.

\section{Funding}

Not applicable.

\section{Publisher's Note}

Springer Nature remains neutral with regard to jurisdictional claims in published maps and institutional affiliations.

Received: 31 August 2018 Accepted: 14 November 2018 Published online: 28 November 2018 


\section{References}

1. Association AN. American Nurses Association's Needlestick Prevention Guide. 2002. Accessed 16 Aug 2011.

2. Foley M, Leyden A. American Nurses Association Independent Study Module, Needlestick Safety and Prevention, 2003. Sótt pann. 2012;2:3-6.

3. Tayaben JL. Compliance with sharps injury prevention guideline among nurses in tertiary care hospitals in the Philippines. Int J Infect Control. 2015;11(2):1-8

4. Hanafi M, Mohamed A, Kassem M, Shawki M. Needlestick injuries among health care workers of University of Alexandria Hospitals. East Mediterr Health Journal. 2011;17:26-35.

5. Halwani MA, Khyat II, Sallam TA. Needle pricks among health care workers in a tertiary care general hospital, Saudi Arabia: a nine-year survey. Dent Stud. 2015:1:9.

6. Hasak JM, Novak CB, Patterson JMM, Mackinnon SE. Prevalence of needlestick injuries, attitude changes, and prevention practices over 12 years in an urban academic hospital surgery department. Ann Surg. 2018;267(2):291-6. https://doi.org/10.1097/SLA.0000000000002178.

7. Musa S, Peek-Asa C, Young T, Jovanovic N. Needle stick injuries, sharp injuries and other occupational exposures to blood and body fluids among health care workers in a general hospital in Sarajevo, Bosnia and Herzegovina. Int J Occup Saf Health. 2014;4(1):31-7.

8. Hutin YJF, Hauri AM, Armstrong GL. Use of injections in healthcare settings worldwide, literature review and regional estimates. BMJ. 2013;3(27):1-3.

9. Saia Mario, Hofmann Friedrich, Sharman Joanna, Abiteboul Dominique, Campins Magda, Burkowitz Joerg, Choe Yoonhee, Kavanagh Shane. Needlestick injuries: incidence and cost in the United States, United Kingdom, Germany, France, Italy, and Spain. Biomed Int. 2010;1:41-9.

10. Singh B, Paudel B, Kc S. Knowledge and practice of health care workers regarding needle stick injuries in a tertiary care center of Nepal. Kathmandu Univ Med J. 2015;51(3):230-3.

11. Adejumo PO, Olatunji BT. Exposure to work-related sharp injuries among nurses in Nigeria. J Nurs Educ Pract. 2014;4(1):229. https://doi. org/10.5430/jnep.v4n1p229.
12. Oluwatosin OA, Oladapo MM, Asuzu MC. Needlestick injuries among health care workers in Ondo State, Nigeria. Int J Med Public Health. 2016:6(1):31-4

13. Akyol A, Kargin C. Needle stick and sharp injuries among nurses. Glob J Nurs Forensic Stud. 2016;1(109):2.

14. Afridi AA, Kumar A, Sayani R. Needle stick injuries—risk and preventive factors: a study among health care workers in tertiary care hospitals in Pakistan. Glob J Health Sci. 2013;5(4):85-92. https://doi.org/10.5539/gjhs. v5n4p85.

15. Clarke Sean P. Hospital work environment, nurse characteristics, and sharps injuries. Am J Infect Control. 2007;35(5):302-9. https://doi. org/10.1016/j.ajic.2006.07.014.

16. Feleke BE. Prevalence and determinant factors for sharp injuries among Addis Ababa Hospitals health professionals. Sci J Public Health. 2013;1(5):189-93. https://doi.org/10.11648/j.sjph.20130105.11.

17. Kelebore WG, Mamo M, Yilma L, Shewalem K, Shakayto S, Kelile M, Getahun D. Assessment of factors affecting needle stick and sharp injuries among health professionals and cleaners in Arba Minch General Hospital, Gamo Gofa Zone, Southern Ethiopia, 2015 G. C. Sci J Public Health. 2016:4(6):463-9. https://doi.org/10.11648/j.sjph.20160406.18.

18. Walle L, Abebe E, Tsegaye M, Franco H, Birhanu D, Azage M. Factors associated with needle stick and sharp injuries among healthcare workers in Felege Hiwot Referral Hospital, Bahir Dar, Northwest Ethiopia: facility based cross-sectional survey. Int J Infect Control. 2013. https://doi. org/10.3396/ijic.v9i4.11709.

19. Dilie A, Amare D, Gualu T. Occupational exposure to needle stick and sharp injuries and associated factors among health care workers in Awi Zone, Amhara Regional State, Northwest Ethiopia, 2016. J Environ Public Health. 2017;2017:2438713. https://doi.org/10.1155/2017/2438713 (Epub 2017 Aug 10)

20. Adams D. Needle stick and sharps injuries: practice update. Nurs Stand. 2012;26(37):49-58. https://doi.org/10.7748/ns.26.37.49.s54.

21. Jakribettu RP, D'souza OL, Pinto VS, Surlu VR, Boloor R, Baliga MS. Needle stick injuries among health care workers in a multispecialty hospital: a retrospective study. Int J Curr Microbiol App Sci. 2017;6(5):833-7.

Ready to submit your research? Choose BMC and benefit from

- fast, convenient online submission

- thorough peer review by experienced researchers in your field

- rapid publication on acceptance

- support for research data, including large and complex data types

- gold Open Access which fosters wider collaboration and increased citations

- maximum visibility for your research: over $100 \mathrm{M}$ website views per year

At BMC, research is always in progress.

Learn more biomedcentral.com/submissions 